\title{
@creative
}

BY-NC-SA 4.0

UMÁTICA. Revista sobre Creación y Análisis de la Imagen

\section{Kassel no invita a la política}

\author{
JUAN JESÚS TORRES (juanjesustorresjurado@gmail.com) \\ JAVIER BERMÚDEZ (javierbperez@gmail.com)
}

Me pregunto sobre las posibilidades de un arte en relación con lo social en la actualidad. Es algo que hemos estado conversando antes, durante y después de nuestra visita a Documenta14. Ese "después" tan importante, que sirve para poner en orden nuestros pensamientos y enrolarnos en la ardua tarea de darles sentido y coherencia.

No sé como fue en tu caso, pero mi estancia en la documenta14 "Learning from Athens" estaba cargada de optimismo, a pesar de la negatividad de las críticas a priori acerca de la exposición que llegaban de los distintos medios artísticos y sobre todo de ese espacio de opiniones ligeras como Facebook, donde la gente intenta arrojar luz deprisa y corriendo de eventos como documenta, donde una visita de dos o tres días se antoja cuanto menos escasa. Recuerdo que te lo comentaba y notaba una cierta desafección respecto al arte en tu respuesta, puede que la misma que es- toy sintiendo yo en este momento, aunque quizás sea aquella que sentiremos el resto de nuestras vidas de no encontrar sentido a toda esta vorágine artística donde da la sensación de que hay algo que no termina de encajar. Quizás la sensación de totalidad o de encontrar uno su sitio a la que hago mención, la posición al respecto, tan sólo cobre cuerpo en ciertos momentos efímeros; en esas ocasiones en las que parece que todo cuadra y que casi siempre vienen marcadas por un libro que nos abre los ojos, un artista que realmente nos sorprende, una conversación entre amigos, que son en definitiva aquellos resortes que provocan que las ideas salten por los aires y uno tenga que volver a buscar de nuevo su lugar. Puede que esta sensación de pérdida o crisis, de no saber cuál es nuestro sitio sea el propio motor de toda esta parafernalia artística. En teoría documenta debería ser un catalizador de estos sentimientos, ese tipo de resorte que antes mencionaba.

CÓMO CITAR ESTE TRABAJO / HOW TO CITE THIS PAPER

Torres, J.J. y Bermúdez, J (2018). Kassel no invita a la política. Umática. Revista sobre Creación y Análisis de la Imagen. 1: 180-188.

http://www.revistas.uma.es/index.php/umatica/issue/current 
En Kassel todo parece más fácil. La lectura del evento se antoja incompleta a consecuencia de la imposibilidad de acudir a las dos sedes que este año albergaban el proyecto. Atenas, la sede griega, propone un diálogo directo con Kassel a través de opuestos y en base a una reactivación de lo público que dote de voz a los oprimidos: concretamente a las víctimas de las políticas de austeridad de la troika y al problema de Europa con los refugiados. La historia también juega un papel importante. Lo cierto es que el discurso curatorial parece coherente cuanto menos en una serie de cuestiones que vinculan documenta con lo público evitando los comisarios que entidades privadas formaran parte del proyecto. El punto de partida, en este sentido, fue loable; acercar el arte a lo social en un intento de alejarlo de la élite que es su contexto habitual. La élite entendida como esos poderes financieros que controlan lo material jugando aquí el arte un papel que quiere distanciarse del propio mercado, apostando por aquello que no se puede vender, un acercamiento conceptual con lo político. El posicionamiento es claro, y así fue informado a través de los canales de comunicación antes del comienzo de la exposición. Pero documenta no daría comienzo el 8 de abril en Atenas, fecha de inauguración, sino que la programación se implementaría antes con el trabajo del comisario Paul B. Preciado y su "Parlamento de los cuerpos", que se podía describir como un espacio donde las sensibilidades marginadas por lo dominante tenían cabida y donde el sentido era una construcción horizontal de voces corales que ponía el acento en la dificultad de encorsetar un cuerpo identitario. La idea de exceder el espacio expositivo queda clara en la propuesta, del mismo modo que el temporal, donde documenta apuesta por un aparato proyectual con distintas sedes a lo largo de las dos ciudades. Quizás tras ello esté la idea de desterritorialización, de negación del propio museo que vincula a documenta con la calle y las personas, en definitiva.

En Kassel el recorrido supera las 20 sedes. Recuerdo que nos llamó la atención el hecho de conocer la ciudad gracias al tránsito entre un espacio y otro, de que la exposición tuviera esa característica que tendía a la diseminación de las fronteras internas del museo en favor de la propia ciudad. Recuerdo la obra de bienvenida en la estación de metro "The Welcoming Gate" que casi fue la primera que vimos. Nuestro recorrido fue ordenado siguiendo paso a paso el que recomendaba el equipo curatorial. Las obras, no obstante, eran las mismas en gran medida aunque con un contexto diferente al de Atenas. Hablamos de élite tanto en las sedes como en ese camino; mirábamos a los espectadores casi reconociéndonos en sus opuestos; recuerdo la precariedad en la que fui yo. Nos sentamos en una cafetería desde la que se podía ver la ciudad, tomando un café tres veces más caro que desde donde escribo, sobre sillas firmadas por Knoll y diseñadas por Eero Saarinen. Todo un juego de opuestos. Tenía mucha ilusión ya que era mi primera vez en un evento de este tipo. Un evento de esos del cual la gente del arte, profesores, profesionales y artistas no dejan de hablar como algo imprescindible que alguien del mundillo no se puede perder. Esta era una cantinela que no paraba de escuchar desde los tiempos en la facultad. No obstante, en aquel momento me sentía alejado de esa posición.

Kassel simboliza la élite. Los problemas del 
sur aquí quedan más alejados. El enfrentamiento con documenta no se aleja del ideal kantiano. Tan sólo vestigios en las obras que hacen referencia a los conflictos reales. El movimiento que justifica, bajo mi punto de vista, a Atenas en Kassel es el apoderamiento que supone la colección de arte contemporáneo ateniense de la sede central de la documenta: el Fridericianum. Una lectura fácil. El resto, resultados a modo de atlas de ciertos proyectos performáticos que se cerraron en Kassel. Entre ellos cabe mencionar los de los españoles Roger Bernat o Daniel G. Andújar. Hay buenas intenciones; al menos un intento, aunque superficial, de retorno político del arte en un evento que sirve -o ha servido históricamente- para sentar las bases de su propio devenir.

Aquí quedaría la diagnosis en ese querer cambiar las cosas, aunque fuera superficialmente. En este sentido, el camino debería conducir, por lógica, a una mayor influencia -en el futuro- del arte en el terreno de lo social y una mayor implicación política por parte de los artistas. Al menos este es uno de los puntos fuertes de esta Documental4. Pero lo superficial quizás pese más que lo político y nos lleve a próximos eventos que no consigan superar aquellos objetivos que se imponen a priori por culpa de sus propias contradicciones internas. Puede que el problema sea ese empecinamiento en mezclar el arte con la política en discursos curatoriales excesivamente cerrados que son, los que a su vez, producen la contradicción que tira por tierra la idea de documenta. Al menos esa es mi sensación después de visitar la muestra. Por ello creo que, aunque todos sabemos la máxima beuysiana que dice "todo hombre es un artista y todo arte es político", en este caso habría que lle- var a cabo un ejercicio de autocrítica y exigir un mayor grado de implicación real a los que dirigen el evento si el discurso de los comisarios pretende este rumbo. El problema estriba en que el propio discurso de documenta no termina de ser coherente ni convincente, pues se cae. Esto convierte la pulsión política del evento en maquillaje que queda muy bien en los diferentes comunicados de prensa.

Revisando la información de lo que deparó la sede ateniense, se podía apreciar que muchos colectivos artísticos quedaron marginados y sin voz y que la dirección de documenta miró hacia otro lado cuando los problemas reales -ya fueran económicos, políticos o relacionados con la crisis de los refugiados- aparecieron. De hecho, el gran programa performático, ya mencionado, el "Parlamento de los cuerpos" también tuvo problemas en su intento por convertirse en un ágora de encuentro horizontal que devino en espacio de conferencias, contexto donde se sabe que la fluidez comunicativa es una quimera debido a las propias reglas intrínsecas en este tipo de situaciones donde todo es al final políticamente correcto. En este sentido de unión arte-vida, la posibilidad del arte de ejercer influencia ante estos problemas se disipa por las contingencias existentes en eventos de este tipo, pues supongo que hay muchos intereses que desconozco y que hay que preservar.

Llegados a este punto me pregunto ¿qué puede el arte, en un evento como éste que elige Atenas como lugar donde lanzar un discurso político, cuando se encuentra con el problema de verdad - la llegada de refugiados a las costas griegas, el desalojo por parte de las autoridades atenienses de espacios ocupados por colectivos artísticos, la 
violencia represiva del estado que se ejerce en la calle contra parte de la población civil? La propia actuación del equipo curatorial al respecto sirve para responder la pregunta: silencio. Aunque quizás el silencio debió haberse dirigido hacia una posición más radical: la clausura, como se deja entrever en la carta abierta a Documental4 por parte del colectivo "Artistas contra los desalojos" que instaba a "abrir los ojos a la ciudad" mientras los visitantes llenaban las calles de Atenas. La proclama decía: "Ahora es un tiempo para crear un espacio para todos, no un momento para hacer archivo cultural de la crisis. Es un momento para la acción, no para el consumo ciego. Le pedimos que redirija sus pasos a las sombras y zonas oscuras, lejos de la fiesta que el alcalde de Atenas ha organizado para usted ${ }^{\prime \prime}$. No estuve en la sede ateniense, pero disfruté mucho de mi visita a Kassel. A fin de cuentas quizás el arte sólo sirva para eso.

¿Qué te parece esta respuesta a tu pregunta? El arte puede hacer productivo el mutismo. Quizás, pienso, el silencio sea el mejor puerto de partida. Los lugares de salida son, por definición, fugaces. y como tales substanciosos para nuestras memorias hambrientas de un edén por supuesto perdido. La utopía es el pasado mejor. El silencio es una quimera de nuestro tiempo. ¿No tienes la sensación de que nos hemos acostumbrado tanto a la brisa que ya no sabemos diferenciarlo del vendaval? Posiblemente, sin atreverme a asegurarlo, sea el momento de callar. Qué enmudezcamos todos. Al mismo tiempo. Ahora. Cuando digo todos me refiero a aquellos, como nosotros, que nacieron

1 En línea: http://esferapublica.org/nfblog/carta-documenta/ en el lado amable. $Y$ a los que aun sin pertenecer han sido abrumados. Si el ruido cesase, de repente, ¿podríamos acaso oír el rumor de unas olas llenas de víctimas? Las del Mediterráneo contaminado de desvergüenza y crueldad, y por qué no decirlo, de fascismo grosero. Probablemente el lugar del arte, el físico -me refiero al museo, cualquier de ellos, o una bienal, cualquiera de ellas, o una Documenta, la de Kassel, o la de Atenas, o la de Kassel/Atenas-, sea aquel que brinda la posibilidad de estar callados. Reconozcamos a veces la inoperancia del lenguaje ante tanto espacio de simulación, entre tanto experimento de tintes póstumos. ¿Acaso no bajamos la voz cuando entramos en la institución que admiramos? No te lo dije, pero cuando tomábamos una cerveza en aquel jardín de Kassel, a la vez que caía la noche, recordaba que en esa mañana soleada de Málaga en la que decidimos acompañarnos hasta la documenta, yo huía de un verano desatado en un sin fin de gritos. A la segunda cerveza ya estaba seguro; nosotros tres estábamos en Kassel en pleitesía al silencio.

Nathalie Heinich ofrece una pregunta; ¿y si el problema de la respuesta se resuelve en la cuestión misma? Para Heinich hay tres tipos de arte ${ }^{2}$. Y lo dice así, toda ella cartesiana. Un arte clásico, el que reconoce el canon tradicional en forma y fondo. Un arte moderno, el revolucionario por subjetivo pero con los medios del primero. Un arte contemporáneo, que supera la materia y los formatos, las interpretaciones y las intenciones. El de ahora. ¡El de la libertad absoluta! El exceso de positivismo va implícito en la ecuación. Bajo el paradigma

2 Heinich, N. Le triple jeu de l'art contemporain. Les Éditions de Minuit. 1998. 


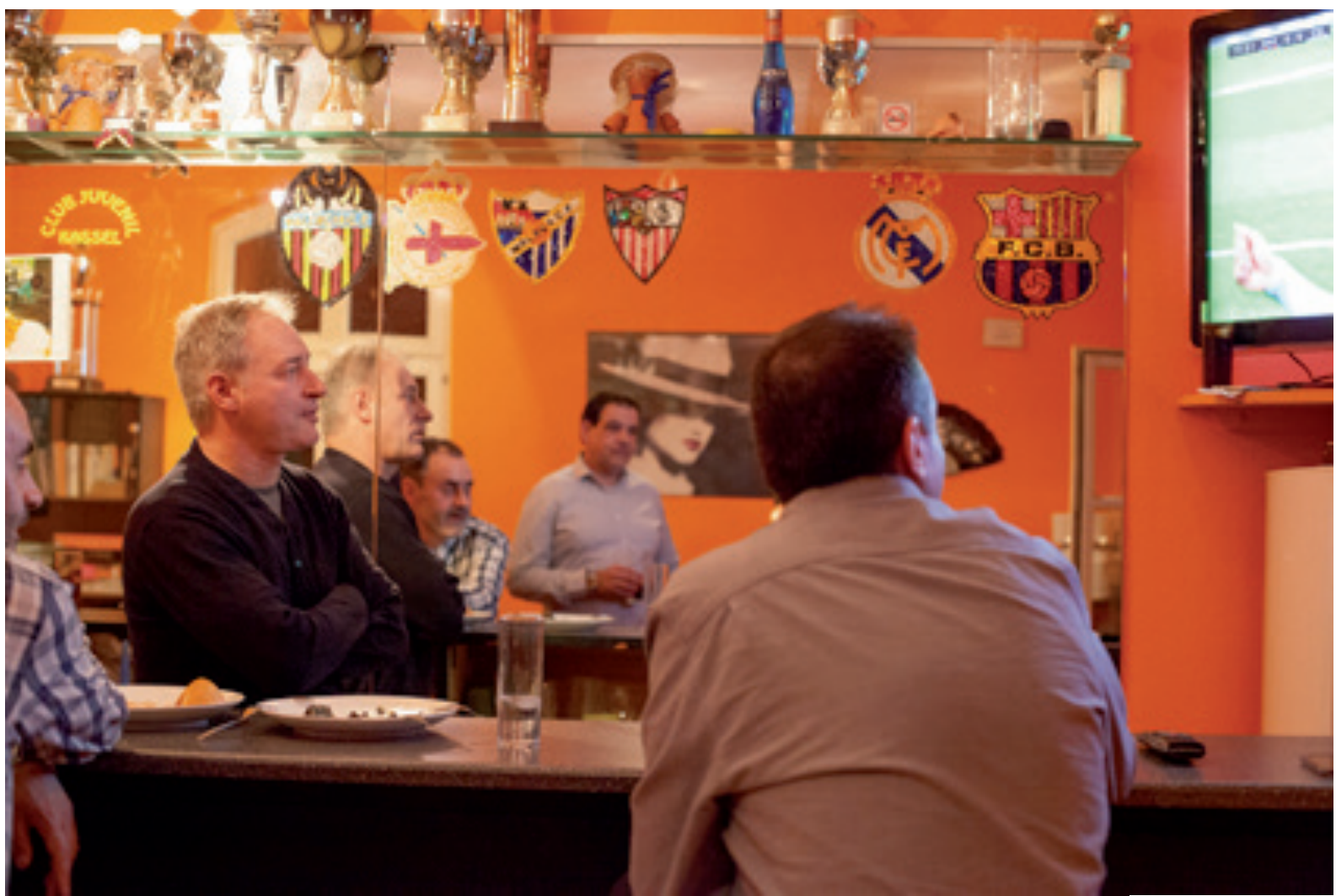

de que el arte es reflejo de una sociedad, la diagnosis viene dada. Uno mira a su alrededor y procura encontrar el parangón en objetos desplegados en habitaciones blancas -o antiguas fábricas de tofu, da igual- como si detrás de cada uno, un ápice de verdad asomase en un discurso incompleto, pero latente. ¿No crees que tanta cita a Rancière, Deleuze o Benjamin no esconden una desesperación por dotar de sentido a un espasmo de egocentrismo? La sociedad - ¿postmoderna? ¿hipermoderna? ¿ciborg? ¿postinternet? ¿postverdad? - produce una plusvalía de información. Una marabunta de discursos de los que el arte quiere rescatar aquella verdad que creemos saber que flota, desplazada o desterritorializada, pero allí, en algún sitio oculto. Nuestra beatitud es enfermiza, siempre al acecho de la fe. La desproporción de positivismo, sugiere Heinich, nos obliga a ver deidad en una exasperante vacuidad. Vida donde hay muerte. La característica definitoria de la muerte es el silencio. Entonces, ¿puede ser que sea nada aquello que grita a voces el arte contemporáneo?
Podría ser, siempre que sigamos empeñados en la comodidad de la contingencia. El silencio es un lugar de proyección, como la pantalla blanca de un cine vacío. En ella todas las películas, de todos los tiempos, se desarrollan a la vez. Al mismo tiempo. Un lienzo, como una carta simulada en una pantalla, es un espacio latente. En silencio. Como en el libro, la significación del absoluto blanco se adquiere cuando se acerca, de alguna manera, a nuestro previo asiento. Ah, es verdad, y me gusta, por eso, porque me recuerda, y mi memoria es cierta. Es experiencia. La práctica es un espacio de verdad. Sin embargo, ¿de verdad vivimos? El simulacro que tanto hemos oído y del que tanto hemos hablado y al que tanto hemos atacado se soslaya con una vida atravesada, incidida, estructurada, por la imagen. Zettabytes de información sobrante. Anodina, repetida. En ese ruido, ¿qué hace el arte? El que me interesa, permanece casi callado. A su sigilosa manera da cuenta de espacios sumergidos en la huella. En el inmenso ruido de artillería que tantos años han construido la
Fig.01.

Ahlam Shibli.

Heimat. Nordhessen, Alemania (2016-17).

Serie de 53

fotografías en copias cromogénicas. 
hegemonía de esta parte del tablero. Entiendo que el concepto que atraviesa todo lo que se expone como arte de nuestro tiempo sea el de reparación, como si eso fuese posible. Como es imposible solucionar tal desastre, parece sensato cartografiar el espacio devastado. Desde el silencio que es otra forma de respeto. En silencio se vela al muerto.

Ahlam Shibli presentó en la Documenta 14 dos trabajos. Uno en Atenas. Otro en Kassel. En el EMST de la capital griega, Occupation, una serie de treinta y dos fotografías que mapean la vida bajo la ocupación violenta de Israel

AUTOR: Juan Jesús Torres es director del Grado en Bellas Artes en TAI (Centro Universitario de Artes) MADRID. Graduado en Bellas Artes por la Universidad de Granada, Master en Investigación en Arte y Creación por la Universidad Complutense de Madrid, Master en Historia del Arte Contemporáneo y Cultura Visual y Doctor Cum Laude en Historia y Artes por la Universidad de Granada. Crítico de arte en diversos medios especializados y con numerosas publicaciones en su haber, ha comisariado diversas exposiciones, destacando FACBA 2017, festival de artes contemporáneas de la Universidad de Granada. juanjesustorresjurado@gmail.com

AUTOR: Javier Bermúdez es crítico de Arte en La Opinión de Málaga. Profesor de Grado en Diseño. EADE Estudios Universitarios. Desarrolla su tesis doctoral "Relaciones liminares entre prácticas artísticas y prácticas curatoriales contemporáneas"

javierbperez@gmail.com en los territorios palestinos de Al-Khalil/Hebron. En la Neue Neue Galerie de Kassel Heimat, cincuenta y tres fotografías tomadas cerca de la ciudad, en el Nordhessen, la zona norte de Hesse, uno de los dieciséis estados federales de Alemania, la casa de muchos de nuestros refugiados. Españoles. Refugiados españoles. Expatriados de un país arrasado por la desidia autoritaria, por las fosas comunes, por la falta de libertades, por las imposiciones, por la pobreza, por la injusticia, por la incultura, por el olvido y por la desesperanza. Un país silenciado. Al frío, a ese idioma, a ese país de pasado cruel, a la posibilidad. Irse. Dejando todo atrás. Familias, amigos, amores, plazas, calles, noches y mañanas. Todo. Imagina. Todo. Por una vida fuera de la locura nacionalista, para poder hablar. Muchos años después aquel país, este, es un lugar más o menos próspero, a punto de fracturarse, a punto de unirse más que nunca. Un país que se consume en tertulias de televisión. Joven y preparado. Como su arte, objetualizado y conceptualizado, lleno de referencias y opiniones, de anglicismos y presencias en redes. Desfile de lo mismo aparentemente renovado, como los novios de Duchamp. De ruido, mucho ruido. Simulando que alguien, al otro lado, escucha. Una mujer palestina, en busca de la voz que explique su mundo en guerra se topa con señores mayores que no han actualizado el diseño de los escudos de los equipos de fútbol de su país natal. En la utopía del pasado mejor, el atavismo del silencio sepulcral, del mirar a otro lado, de la pertenencia a parte, de formar el otro, exactamente el mismo que dejamos ahogarse a kilómetros de nuestros resorts. Creo que hay política en Kassel cuando funciona como sinónimo de arte contemporáneo. Sólo que no habla tan 